\title{
Lipoprotein (a) as a residual risk factor for atherosclerotic renal artery stenosis in hypertensive patients: a hospital-based cross-sectional study
}

\author{
Xiangming $\mathrm{Hu}^{1,2}$, Xing Yang ${ }^{3}$, Xida $\mathrm{Li}^{3}$, Demou Luo ${ }^{4}$, Yingling Zhou ${ }^{4^{*}}$ and Haojian Dong ${ }^{4^{*}}$ (D)
}

\begin{abstract}
Background: Low-density lipoprotein cholesterol (LDL-C) has been proven to be a risk factor for atherosclerotic cardiovascular disease (CVD), while lipoprotein (a) (Lp(a)) is a residual risk factor for CVD, even though LDL-c is well controlled by statin use. Importantly, the role of $L p(a)$ in atherosclerotic renal artery stenosis (ARAS) is still unknown.

Methods: For this hospital-based cross-sectional study, patients who simultaneously underwent coronary and renal angiography were examined. ARAS was defined as a 50\% reduction in the cross-sectional (two-dimensional plane) area of the renal artery. Data were collected and compared between ARAS and non-ARAS groups, including clinical history and metabolite profiles. Univariate analysis, three tertile LDL-c-based stratified analysis, and multivariateadjusted logistic analysis were conducted, revealing a correlation between Lp(a) and ARAS.

Results: A total of 170 hypertensive patients were included in this study, 85 with ARAS and 85 with non-RAS. Baseline information indicated comparability between the two groups. In the univariate and multivariate analysis, common risk factors for atherosclerosis were not significantly different. Stratified analysis of LDL-c revealed a significant increase in the incidence of ARAS in patients who had high Lp(a) concentrations at low LDL-c levels (odds ratio (OR): 4.77, 95\% confidence interval $(\mathrm{Cl}): 1.04-21.79, P=0.044)$. Further logistic analysis with adjusted covariates also confirmed the result, indicating that high $L p(a)$ levels were independently associated with ARAS (adjusted OR (aOR): 6.14, 95\%Cl: 1.03-36.47, $P=0.046)$. This relationship increased with increasing $L p(a)$ concentration based on a curve fitting graph. These results were not present in the low and intermediate LDL-clevel groups.
\end{abstract}

Conclusion: In hypertensive patients who present low LDL-c, high Lp(a) was significantly associated with atherosclerotic renal artery stenosis and thus is a residual risk factor.

Keywords: Lipoprotein (a), Atherosclerotic renal artery stenosis, LDL-cholesterol, Residual risk

\footnotetext{
*Correspondence: zylgdh@163.com; donghaojian@sina.com

${ }^{4}$ Department of Cardiology, Vascular Center, Guangdong Cardiovascular Institute, Guangdong Provincial Key Laboratory of Coronary Heart Disease Prevention, Guangdong Provincial People's Hospital, Guangdong Academy of Medical Sciences, \#96 Dongchuan Road, Guangzhou 510080, Guangdong, China

Full list of author information is available at the end of the article
}

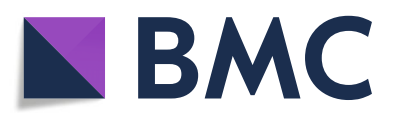

(- The Author(s). 2020 Open Access This article is licensed under a Creative Commons Attribution 4.0 International License, which permits use, sharing, adaptation, distribution and reproduction in any medium or format, as long as you give appropriate credit to the original author(s) and the source, provide a link to the Creative Commons licence, and indicate if changes were made. The images or other third party material in this article are included in the article's Creative Commons licence, unless indicated otherwise in a credit line to the material. If material is not included in the article's Creative Commons licence and your intended use is not permitted by statutory regulation or exceeds the permitted use, you will need to obtain permission directly from the copyright holder. To view a copy of this licence, visit http://creativecommons.org/licenses/by/4.0/. The Creative Commons Public Domain Dedication waiver (http://creativecommons.org/publicdomain/zero/1.0/) applies to the data made available in this article, unless otherwise stated in a credit line to the data. 


\section{Background}

Cardiovascular disease (CVD) is a leading cause of deaths in China and a large proportion of CVD cases are caused by arteriosclerotic cardiovascular disease (ASCVD). The number of deaths arising from ASCVD has rapidly and substantially increased, and it was responsible for $>2.4$ million deaths in 2016 and accounting for $25 \%$ of total deaths [1]. Mendelian randomization studies and RCTs have consistently demonstrated that low-density lipoprotein cholesterol (LDL-c) is causally associated with the risk of ASCVD [2-7]. The American Heart Association/American College of Cardiology and European Society of Cardiology guidelines provide recommended LDL-c levels based on CVD risk stratification. In a recent ESC article, lipoprotein (a) [Lp(a)] was highlighted as a CVD risk estimator [8]. Studies from the past few decades have revealed that populations with well-regulated LDL-c levels still had a considerably high residual cardiovascular risk, and that $\mathrm{Lp}(\mathrm{a})$ is responsible for this phenomena [9-14].

Atherosclerotic renal artery stenosis (ARAS), which represents a considerable proportion of ASCVD cases, is generally recognized to cause renal damage and accounts for $5-15 \%$ of patients who develop end-stage renal disease [15-17]. The incidence of symptomless ARAS has been reported to be high in patients undergoing angiography for extrarenal atherosclerotic vascular disease, especially in hypertensive patients [18], reflecting the prevalence of ARAS in systemic atherosclerosis, and it is usually overlooked [19, 20]. Hypertension can accelerate the progress of ARAS by facilitating lipid deposition, in addition to other traditional CVD risk factors, such as age [21, 22], diabetes [23] and smoking [24], which are also related to ARAS. Therefore, the question: does $\mathrm{Lp}(\mathrm{a})$ act as a "residual risk" factor for ARAS in hypertensive patients? is worthy to explore. Recent studies have suggested a relationship between Lp(a) and ARAS [25, 26], but further evidence is required to clarify this relationship, which is the aim of this study.

\section{Methods}

\section{Study population and data collection}

This study was designed as a cross-sectional analysis. From October 2013 to September 2014, patients with hypertension who had simultaneously undergone both coronary and renal angiography with hypertension were consecutively selected from a single catheter center in China. Initially, patients underwent coronary angiography because of suspected severe coronary artery disease (CAD), and renal angiography was also performed if the patient satisfied any of the following conditions: patients who developed hypertension before age 30; patients who developed severe hypertension after age 55; patients with rapid, refractory, malignant, or suddenly aggravated hypertension; patients with deteriorated renal function (as marked by a $>30 \%$ increase in serum creatinine) after treatment with angiotensin-converting enzyme inhibitors or angiotensin receptor blockers; patients with unexplained renal atrophy or $>1.5-\mathrm{cm}$ difference in length of kidney; patients with unexplained sudden exacerbated and/or refractory pulmonary edema; patients with coronary multivessel disease, cerebrovascular disease, or peripheral atherosclerotic disease; patients with unexplained exacerbation of renal failure (including patients undergoing dialysis or kidney transplantation); or patients with unexplained congestive heart failure. Exclusion criteria included a history of cancer, coagulation disorder, or renal stenting.

All experimental data were collected from the case database of the medical center and recorded by two authors (Yang and Li).

\section{Definitions and laboratory examination}

In all patients, hypertension was diagnosed according to the European Society of Cardiology guidelines as SBP $\geq$ 140 and/or $\mathrm{DBP} \geq 90 \mathrm{mmHg}$, which is equivalent to a 24-h ambulatory blood pressure monitoring average of $\geq 130 / 80 \mathrm{mmHg}$, or a home blood pressure monitoring average of $\geq 135 / 85 \mathrm{mmHg}$ for two measurements at least 3 days [27]. Diabetes status was diagnosed based on presence of diabetes. If the patient had a negative history of diabetes, the repeatedly fasting blood glucose $\geq 7.0$ $\mathrm{mmol} / \mathrm{L}(126 \mathrm{mg} / \mathrm{dL})$ or haemoglobin $\mathrm{A} 1 \mathrm{c} \geq 6.5 \%$ or oral glucose tolerance test positive test ( $2 \mathrm{~h}$ plasma glucose $\geq 11.1 \mathrm{mmol} / \mathrm{L}(200 \mathrm{mg} / \mathrm{dL})$ ) were adopted to define diabetes status according to the European Society of Cardiology guidelines [28]. Blood cell test was detected using a Sysmex-XE5000 through impedance technology. HDLcholesterol, LDL-cholesterol, total-cholesterol, Lp(a), albumin, uric acid, creatinine, and cystatin $\mathrm{C}$ were detected using a Backman AU5800 spectrophotometer via colorimetry or immunoturbidimetry. Aldosterone, renin, and angiotensin II were detected using a PETECK96-I through a chemiluminescence immunoassay. The evaluated glomerular filtration rate (eGFR) $\left(\mathrm{mL} \cdot \mathrm{min}^{-1} \cdot 1.73\right.$ $\mathrm{m}^{-2}$ ) was calculated using the Cockroft-Gault formula.

Coronary and renal angiography was performed by the Judkins technique. CAG and renal angiography were performed simultaneously with radial approach, and the femoral artery was used in a minority of patients as clinically necessary. Catheter 5-Fr or 6-Fr Judkins left and right diagnostic catheters (Cordis, Bridgewater, NJ, USA) were used for left and right coronary angiography, respectively. Renal angiography was performed using a 5-Fr Judkins right or 5-Fr Multi-Purpose diagnostic catheter engaged in or directed to the renal artery ostium, with contrast medium flowing back from the renal artery. Both 
renal arteries were visualized in anterior-posterior projections. All angiograms were independently reviewed by an experienced angiographer. Lesion severity in the coronary tree and the renal vasculature was assessed by visual estimation. ARAS was defined as a $50 \%$ reduction in the area of cross-sectional or two-dimensional plane of the renal artery, as presented by renal arterial lumen loss (RALL) $\geq 50 \%$. As suggested by American College of Cardiology and Chinese Cardiovascular Disease Association in 2016 $[29,30], a \geq 70 \%$ luminal diameter narrowing of an epicardial stenosis or $\geq 50 \%$ luminal diameter narrowing of the left main artery made by visual assessment were regarded as severe CAD to identify those with high-risk atherosclerotic factors. Peripheral arterial disease (PAD) was defined by one or more of the following conditions: intermittent claudication symptoms; previous surgery for lower limb arterial; angiography showing the presence of significant stenosis in the lower limbs/subclavian/carotid/vertebral artery and abdominal aortic aneurysm.

\section{Statistical analysis}

Statistical analysis was performed in three steps. First, the baseline characteristics of the participants were measured according to following principles after they were divided into two groups (ARAS and non-ARAS): (1) continuous variables were expressed as the means \pm standard deviations (for normal distribution) or medians/quartiles (for skewed distribution), and categorical variables were shown as the frequencies with percentages; (2) T-test for normal distribution data, Mann-Whitney $U$ test for skewed distribution data, and chi-square test/Fisher's exact test for categorical variables were used to determine significant differences between the groups. Next, univariate and multivariate analysis were conducted to find potential risk factors. Then, given that until now, there is no clear standard for stratification related to Lp(a), an LDL-cbased stratified analysis was conducted to assess the relation between $\mathrm{Lp}(\mathrm{a})$ and ARAS. Finally, age, gender, BMI, current smoking status and DM that regarded as common atherosclerosis risk factors were pooled for multivariate adjustment by logistic analysis and used to assemble generalized additive models to identify non-linear relationships where $\mathrm{Lp}(\mathrm{a})$ was a continuous variable. If an incremental effect model was present, it was trimmed into three tertiles to determine the threshold point for risk assessment. Comparisons where $P<0.05$ (two-sided) were considered to be statistically significant. All of the analyses were performed with Stata 15.0, R (version 3.4.3) and EmpowerStats (http://www.empowerstats.com, X\&Y Solutions, Inc., Boston, MA).

\section{Result}

Baseline information

A total of 170 hypertensive patients were analyzed in this study. Based on the RALL range, these patients were divided into two groups: ARAS (RALL $250 \%$ ) and nonARAS (RALL < 50\%). All baseline characteristics are included in Table 1 . The median age of the participants was 69 years and male accounted for $64.71 \%$ of the study population. Of these, 22 patients had bilateral renal artery stenosis, 63 patients had unilateral renal artery stenosis, and 85 patients did not have renal artery stenosis. SBP, CAD, PAD and calcium channel blockers used were found to be significantly different between two groups. Table 2 details the metabolites levels for the patients, in which creatinine, eGFR, and aldosterone were significantly different between the patient groups.

\section{Univariate, multivariate and stratified analysis}

We conducted both univariate and multivariate analysis of ARAS the results were shown in Table 3. In the univariate and multivariate analysis, age, gender, body mass index (BMI), current smoking status,

Table 1 Baseline characteristics of ARAS and non-ARAS patients

\begin{tabular}{|c|c|c|c|c|}
\hline & $\begin{array}{l}\text { TOTAL } \\
N=170\end{array}$ & $\begin{array}{l}\text { ARAS } \\
N=85\end{array}$ & $\begin{array}{l}\text { Non-ARAS } \\
N=85\end{array}$ & $P$ value \\
\hline Age (year) & $\begin{array}{l}69.00 \\
(62.00-75.00)\end{array}$ & $\begin{array}{l}72.00(64.00 \\
-76.00)\end{array}$ & $\begin{array}{l}68.00(61.00 \\
-74.00)\end{array}$ & 0.062 \\
\hline Male & $110(64.71)$ & $57(67.06)$ & $53(62.35)$ & 0.521 \\
\hline $\begin{array}{l}\text { Body Mass Index } \\
(\mathrm{kg} / \mathrm{m} 2)\end{array}$ & $\begin{array}{l}23.93(22.15 \\
-25.82)\end{array}$ & $\begin{array}{l}23.73(21.64 \\
-25.78)\end{array}$ & $\begin{array}{l}24.03(22.59 \\
-26.12)\end{array}$ & 0.214 \\
\hline Current smoking & $51(30.00)$ & $30(35.29)$ & $21(24.71)$ & 0.132 \\
\hline $\begin{array}{l}\text { Systolic blood } \\
\text { pressure }(\mathrm{mmHg})\end{array}$ & $147.08 \pm 24.01$ & $\begin{array}{l}151.72 \pm \\
26.66\end{array}$ & $\begin{array}{l}142.44 \pm \\
20.14\end{array}$ & 0.011 \\
\hline $\begin{array}{l}\text { Diastolic blood } \\
\text { pressure }(\mathrm{mmHg})\end{array}$ & $77.64 \pm 11.57$ & $\begin{array}{l}77.79 \pm \\
11.58\end{array}$ & $\begin{array}{l}77.48 \pm \\
11.63\end{array}$ & 0.864 \\
\hline Diabetes mellitus & $68(40.00)$ & $33(38.82)$ & $35(41.18)$ & 0.754 \\
\hline $\begin{array}{l}\text { Coronary artery } \\
\text { disease }\end{array}$ & 139 (81.76) & $63(74.12)$ & $76(89.41)$ & 0.010 \\
\hline $\begin{array}{l}\text { Peripheral arterial } \\
\text { disease }\end{array}$ & $43(25.29)$ & 28 (32.94) & $15(17.65)$ & 0.022 \\
\hline Antihypertensive & $166(97.65)$ & $83(97.65)$ & $83(97.65)$ & $1.000^{*}$ \\
\hline ACEIs/ARBs & $134(78.82)$ & $62(72.94)$ & $72(84.71)$ & 0.060 \\
\hline $\begin{array}{l}\beta \text {-receptor } \\
\text { blockers }\end{array}$ & $121(71.18)$ & $59(69.41)$ & $62(72.94)$ & 0.611 \\
\hline $\begin{array}{l}\text { Calcium channel } \\
\text { blockers }\end{array}$ & $84(49.41)$ & $51(60.00)$ & $33(38.82)$ & 0.006 \\
\hline Diuretics & $47(27.65)$ & $23(27.06)$ & $24(28.24)$ & 0.864 \\
\hline $\begin{array}{l}\text { a-receptor } \\
\text { blockers }\end{array}$ & $11(6.47)$ & $9(10.59)$ & $2(2.35)$ & $0.057^{*}$ \\
\hline Statin & $10(5.88)$ & $4(4.71)$ & $6(7.06)$ & $0.746^{*}$ \\
\hline
\end{tabular}

Abbreviations: ACEls Angiotensin converting enzyme inhibitors, $A R B S$ Angiotensin receptor blockers

*Fisher's exact test 
Table 2 Metabolites in ARAS and non-ARAS patients

\begin{tabular}{|c|c|c|c|c|}
\hline & $\begin{array}{l}\text { TOTAL } \\
N=170\end{array}$ & $\begin{array}{l}\text { ARAS } \\
N=85\end{array}$ & $\begin{array}{l}\text { Non-ARAS } \\
N=85\end{array}$ & $P$ value \\
\hline Total-cholesterol (mmol/L) & $4.50(3.77-5.41)$ & $4.50(3.80-5.31)$ & $4.52(3.68-5.58)$ & 0.437 \\
\hline Triglyceride $(\mathrm{mmol} / \mathrm{L})$ & $1.42(1.02-2.04)$ & $1.38(1.05-2.02)$ & $1.46(0.99-2.12)$ & 0.410 \\
\hline HDL-cholesterol (mmol/L) & $0.97(0.83-1.15)$ & $0.98(0.83-1.15)$ & $0.96(0.83-1.15)$ & 0.821 \\
\hline LDL-cholesterol (mmol/L) & $2.66(2.11-3.34)$ & $2.66(1.97-3.20)$ & $2.62(2.20-3.49)$ & 0.272 \\
\hline Lipoprotein (a) (mg/L) & $171.73(79.50-376.75)$ & $171.00(74.73-535.75)$ & $172.46(95.00-322.00)$ & 0.173 \\
\hline Hemoglobin ( $\mathrm{g} / \mathrm{L})$ & $125.50 \pm 18.89$ & $124.88 \pm 20.08$ & $126.12 \pm 17.72$ & 0.668 \\
\hline Platelet $\left({ }^{*} 10 \wedge 9 / \mathrm{L}\right)$ & $210.65(178.00-259.50)$ & $209.40(174.00-244.00)$ & $211.00(180.00-263.00)$ & 0.206 \\
\hline Albumin (g/L) & $35.79(32.70-38.20)$ & $35.70(33.40-38.40)$ & $35.90(32.52-37.88)$ & 0.378 \\
\hline Uric Acid $(\mu \mathrm{mol} / \mathrm{L})$ & $408.95(331.50-482.25)$ & $408.90(324.00-489.00)$ & $409.00(339.00-477.50)$ & 0.921 \\
\hline Creatinine $(\mu \mathrm{mol} / \mathrm{L})$ & $97.50(77.67-136.75)$ & $105.48(87.40-148.30)$ & $89.00(68.43-120.00)$ & 0.008 \\
\hline Cystatin C (mg/L) & $1.23(0.99-1.56)$ & $1.25(1.03-1.77)$ & $1.15(0.91-1.54)$ & 0.056 \\
\hline eGFR $\left(\mathrm{ml} /\left(\min \cdot 1.73 \mathrm{~m}^{2}\right)\right)$ & $56.03(38.82-72.04)$ & $47.97(34.91-64.94)$ & $62.70(44.53-77.98)$ & $<0.001$ \\
\hline Aldosterone (nmol/L) & $0.29(0.20-0.50)$ & $0.33(0.22-0.53)$ & $0.24(0.19-0.42)$ & 0.048 \\
\hline Renin $(\mathrm{nmol} / \mathrm{L})$ & $0.62(0.21-1.70)$ & $0.71(0.28-2.00)$ & $0.46(0.13-1.09)$ & 0.194 \\
\hline Angiotensin-II (ng/L) & $46.50(35.00-82.55)$ & $48.00(36.00-83.00$ & $45.00(34.40-81.00)$ & 0.372 \\
\hline
\end{tabular}

Lp(a), LDL-c and diabetes mellitus (DM) were not associated with ARAS. Sensitivity analysis also found that previous antihypertensive and lipid-lowering therapy were not associated with ARAS (Additional file 1: Table S1). In order to explore the relationship between $\operatorname{Lp}(\mathrm{a})$ and ARAS in a low LDL-c population, a stratified analysis was performed using three tertiles. In a low LDL-c population $(\leq 2.29 \mathrm{mmol} / \mathrm{L})$, patients with high $L p(a)$ levels had significantly higher rates of ARAS than patients with low Lp(a) levels (Table 4, odds ratio (OR): 4.77; 95\% confidence interval $(\mathrm{CI})$ : 1.04-21.79; $P=0.044$ ).

Table 3 Univariate and multivariate analysis for ARAS

\begin{tabular}{|c|c|c|c|c|}
\hline \multirow[t]{2}{*}{ Variable } & \multicolumn{2}{|l|}{$\underline{\text { Univariate }}$} & \multicolumn{2}{|l|}{ Multivariate } \\
\hline & OR (95\%Cl) & $P$ value & OR (95\%Cl) & $P$ value \\
\hline Age & $1.03(1.00,1.07)$ & 0.064 & $1.03(0.99,1.06)$ & 0.123 \\
\hline Male & $1.23(0.65,2.31)$ & 0.521 & $0.97(0.47,2.01)$ & 0.937 \\
\hline Body Mass Index & $0.94(0.86,1.03)$ & 0.216 & $0.97(0.88,1.07)$ & 0.511 \\
\hline Current smoking & $1.66(0.86,3.23)$ & 0.134 & $1.67(0.79,3.56)$ & 0.182 \\
\hline \multicolumn{5}{|l|}{ Lp(a) tertile } \\
\hline Low & 1.0 & & 1.0 & \\
\hline Intermediate & $0.54(0.26,1.15)$ & 0.109 & $0.55(0.25,1.20)$ & 0.134 \\
\hline High & $1.07(0.51,2.25)$ & 0.851 & $1.14(0.53,2.48)$ & 0.733 \\
\hline \multicolumn{5}{|l|}{ LDL-c tertile } \\
\hline Low & 1.0 & & 1.0 & \\
\hline Intermediate & $0.75(0.36,1.58)$ & 0.455 & $0.78(0.36,1.68)$ & 0.523 \\
\hline High & $0.63(0.30,1.32)$ & 0.226 & $0.70(0.32,1.54)$ & 0.370 \\
\hline Diabetes mellitus & $0.91(0.49,1.68)$ & 0.754 & $0.76(0.40,1.46)$ & 0.408 \\
\hline
\end{tabular}

Illustration: "Low" $(\mathrm{OR}=1)$ as the reference

\section{Logistic analysis}

A logistic analysis was performed to identify additional risk factors besides $\mathrm{Lp}(\mathrm{a})$ among populations with low LDL-c levels. The incidence of ARAS dramatically increased in patients with high $\mathrm{Lp}(\mathrm{a})$ levels after adjusting for other influence (adjusted OR (aOR): 6.14, 95\%CI: 1.03-36.47, $P=0.046$ ), including age, gender, BMI, current smoking status and DM (Fig. 1). In the sensitivity analysis by including the previous antihypertensive and lipid-lowering therapy for adjusting, we found the association between Lp (a) and ARAS remained the same with $\mathrm{aOR}=4.13$ in low level of LDL-c patients.

Table 4 LDL-c-based stratified analyses for Lp(a) and ARAS by three tertiles

\begin{tabular}{lcc}
\hline Variable & OR $(95 \% \mathrm{Cl})$ & $P$ value \\
\hline Lp(a) tertile in low LDL-c subgroup & \\
Low & 1.0 & \\
Intermediate & $0.90(0.26,3.07)$ & 0.867 \\
High & $4.77(1.04,21.79)$ & 0.044
\end{tabular}

$\mathrm{Lp}(\mathrm{a})$ tertile in intermediate LDL-c subgroup

$\begin{array}{lll}\text { Low } & 1.0 & \\ \text { Intermediate } & 0.17(0.04,0.81) & 0.026 \\ \text { High } & 0.57(0.17,1.96) & 0.374\end{array}$

Lp(a) tertile in high LDL-c subgroup

$\begin{array}{lll}\text { Low } & 1.0 & \\ \text { Intermediate } & 0.77(0.20,2.92) & 0.700 \\ \text { High } & 0.75(0.19,2.92) & 0.678\end{array}$

Illustration: "Low" $(\mathrm{OR}=1)$ as the reference 


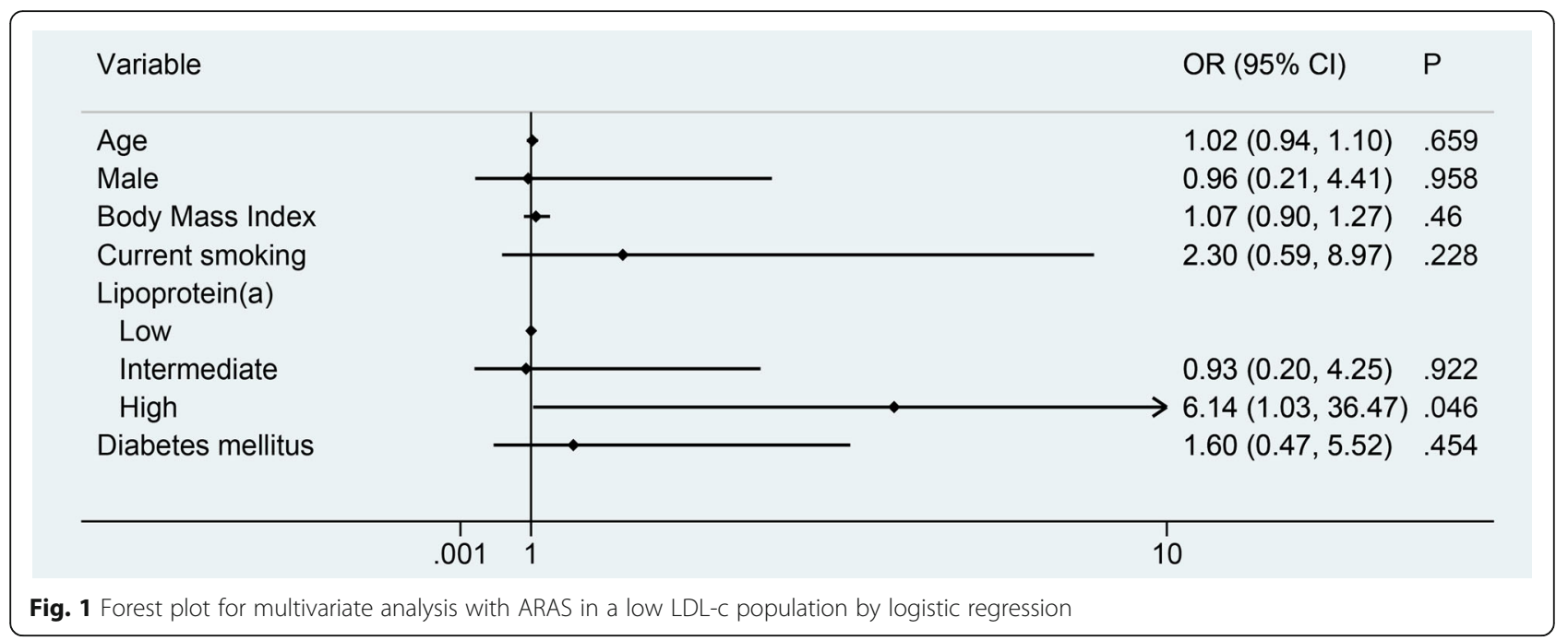

\section{The relationship between $\mathrm{Lp}(\mathrm{a})$ and ARAS in a low LDL-C population}

Based on the logistic regression analysis, the incidence of ARAS was set as the endpoint, with the Lp(a) concentration acting as the main influence factor in plotting the fitting graph and adjusting for other covariates. The relationship between $\mathrm{Lp}(\mathrm{a})$ and ARAS was non-linear, with ARAS levels leveling off at a certain concentration of $\mathrm{Lp}(\mathrm{a})$ (Fig. 2a). As Lp(a) was a continuous variable, three points could be used to represent different thresholds of morbidity. Compared with the low $\mathrm{Lp}(\mathrm{a})$ concentration group, the high $\mathrm{Lp}$ (a) concentration group was significantly related to the incidence of ARAS $(P=0.046)$, while differences in comparison to the intermediate group were not significant $(P=0.922)$. The probability of a patient with low LDL-c levels suffering from ARAS was calculated for different levels of $\mathrm{Lp}(\mathrm{a})$ (Fig. 2b).

\section{The distribution of $\mathrm{Lp}(\mathrm{a})$ in population}

Setting $\mathrm{Lp}(\mathrm{a})$ concentration as the continuous variable, the concentration demarcation point was set using the Lp(a) tertile method on the study population in order to obtain risk stratification. The distribution of $\mathrm{Lp}$ (a) was positively skewed to the right, and ARAS risk was significantly increased in the upper tertile in low LDL-c patients (Fig. 3).

\section{Discussion}

This cross-sectional study indicated that, in a hypertensive Chinese population with low levels of LDL-c, Lp(a) was identified as a significant residual risk factor for ARAS.

The result was performed in five parts. Firstly, in univariate analysis and multivariate analysis, age, gender, BMI, current smoking status, Lp(a), LDL-c and DM were not associated with ARAS. Secondly, we analyzed different concentrations of $\mathrm{Lp}(\mathrm{a})$ in a low LDL-c population, revealing that high-levels of $\mathrm{Lp}(\mathrm{a})$ were associated with a high incidence rate of ARAS, further supporting the hypothesis that ARAS and $\mathrm{Lp}(\mathrm{a})$ levels are related. Next, logistic analysis that adjusted for other covariates in this low LDL-c population to further confirmed the hypothesis. After controlling for age, gender, BMI, current smoking and DM, we found that there was a significant effect of $\mathrm{Lp}(\mathrm{a})$ on ARAS in a low LDL-c population. Subsequently, in order to more intuitively demonstrate this relationship with ARAS, a concentration-prevalence fitting curve was plotted, revealing that incremental increases in $\mathrm{Lp}$ (a) concentration of Lp(a) initially caused increased ARAS levels, before leveling off at a certain rate. At the same time, Lp(a) concentration was divided into three tertiles in order to generate a line chart to estimate risk proportions. Finally, the distribution of $\operatorname{Lp}(\mathrm{a})$ concentrations and the tertile $\mathrm{Lp}(\mathrm{a})$ point in hypertensive patients were analyzed to distinguish different population based on ARAS risk. To our knowledge, we are the first to demonstrate an independent association between $\operatorname{Lp}(\mathrm{a})$ concentration and ARAS in the hypertensive low LDL-c population.

Pathophysiologically, the mechanisms by which $\mathrm{Lp}$ (a) increases CVD risk are driven by proatherogenic and prothrombotic states, including endothelial disorder, smooth muscle proliferation, foam cell formation, and local coagulation disturbances [13]. Molecularly, $\mathrm{Lp}(\mathrm{a})$ is similar to LDL-c, as it is a particle covalently bound by apoB and apo (a), which carries pathogenic LDL-c and leads to atherosclerosis [31]. However, Lp(a) is more atherogenic than LDL-c due to the presence of apo (a), which can induce inflammation that is mediated by oxidized phospholipids and antifibrinolytic effects that result from inhibiting 


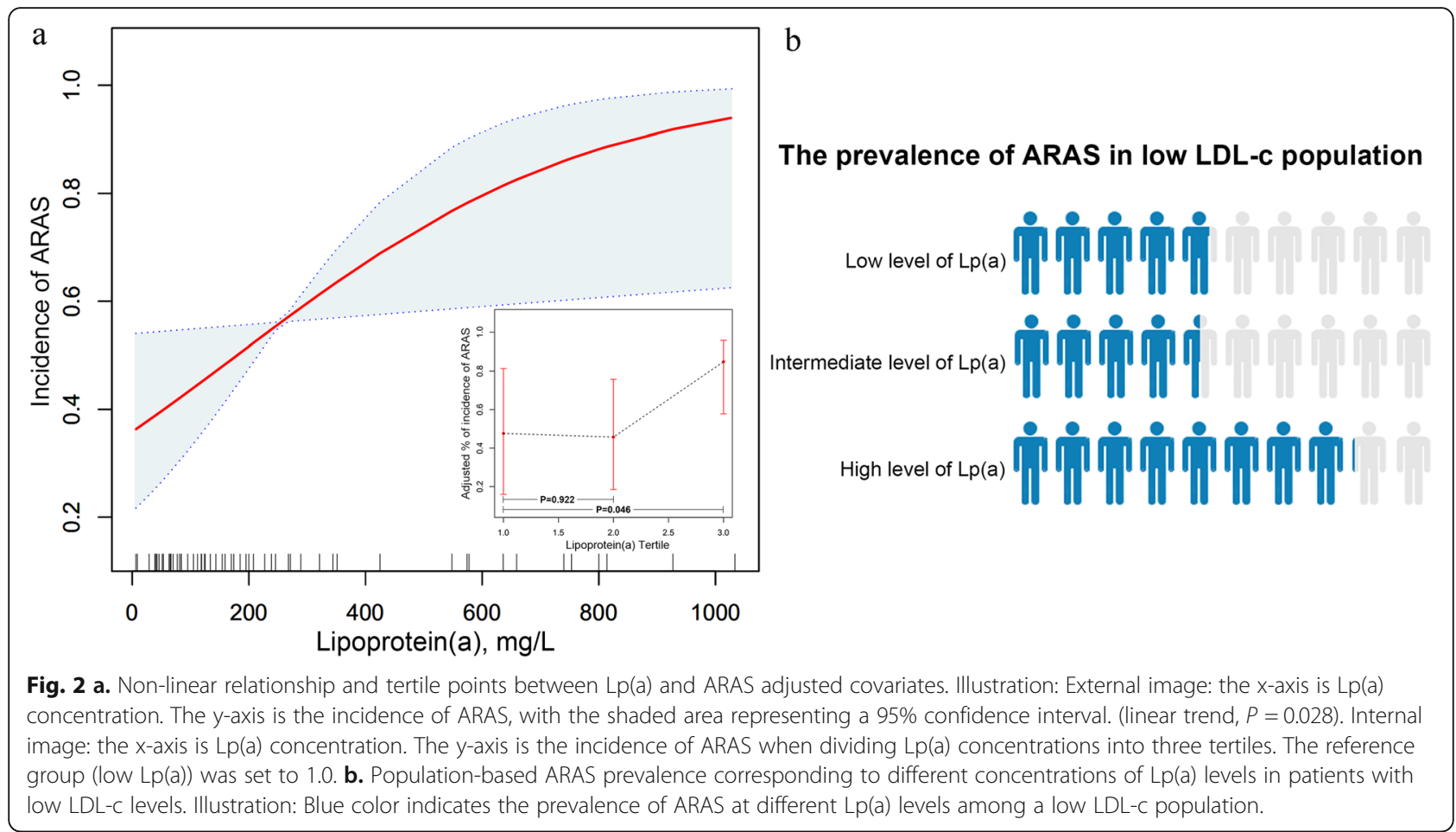

plasminogen activation [31-34]. Lp(a) shares similarities to LDL-c, which may account for the associated risk of $L p(a)$ leading to atherosclerosis initiation and progression in a low LDL-c environment. In this study, $L p(a)$ levels were significantly associated with ARAS at low LDL-c levels. One explanation for this effect is that the impact of $\operatorname{Lp}(a)$ is reduced at high LDL-c concentrations. Although $\mathrm{Lp}(\mathrm{a})$ has a stronger pathogenicity, LDL-c is still a significant factor in atherosclerosis progression. Together, this underscores the importance of $\mathrm{Lp}(\mathrm{a})$ in the context of low LDL-c levels and promotes further study of the related residual risks.

Clinical trials and systematic reviews over the past several decades have revealed a strong relationship between Lp(a) concentration and CVD [35-39]. For example, the JUPITER trial of low LDL-c participants demonstrated that baseline $\mathrm{Lp}(\mathrm{a})$ concentrations were associated with

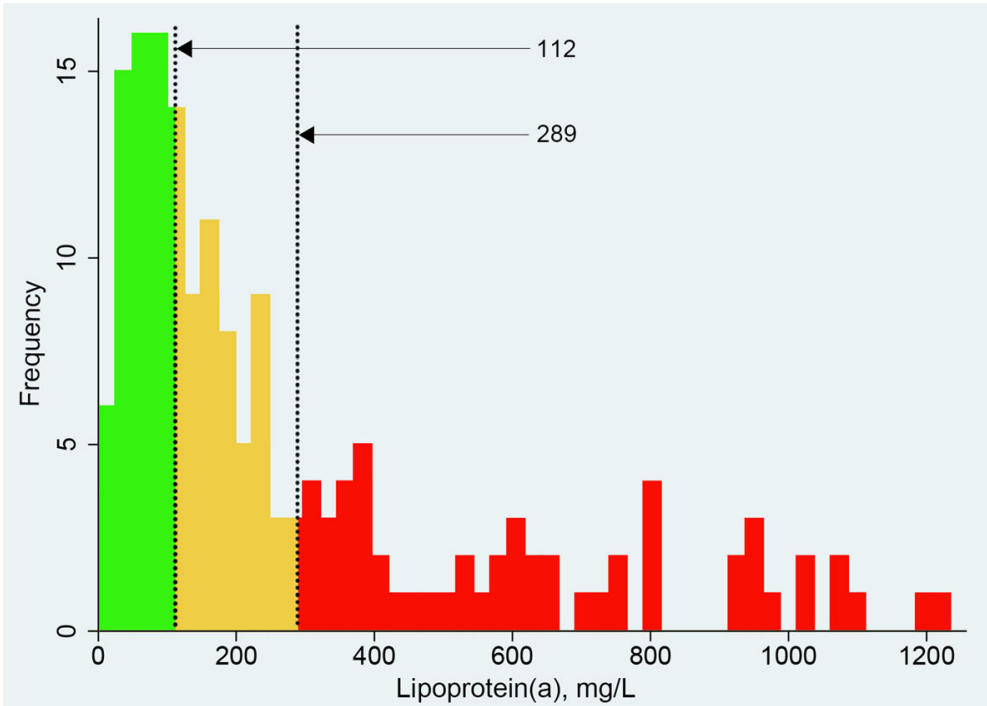

Fig. 3 Distribution of $L p(a)$ concentrations in a population. Illustration: Red bars ( $L p(a)>289 \mathrm{mg} / \mathrm{L}$ ) represent increased possibility of suffering from ARAS at low LDL-c levels 
increased CVD risk [14]. Similar results were obtained from AIM-HIGH and LIPID trials in which participants underwent LDL-c lowering therapy $[40,41]$. These data suggest that high $\mathrm{Lp}(\mathrm{a})$ levels act as a latent pathogenic factor during the development and treatment of CVD wherein common risks are treated. This study examining the relationship between ARAS and $L p(a)$ supports these observations, indicating that $\mathrm{Lp}(\mathrm{a})$ is a determinant for residual risk in hypertensive patients with low LDL-c levels. In the general population, $L P A$ is the major gene controlling the $L p(a)$ feature and explains $70-90 \%$ of the variance in $\mathrm{Lp}(\mathrm{a})$ levels [42]. In this study, most patients had undergone primary angiographic without statin treatment, so their baseline $\mathrm{Lp}(\mathrm{a})$ levels were mostly controlled by genetics, suggesting that the study's results are applicable to those with naturally high Lp(a) levels. This cannot be inferred across the entire population, as widespread use of statins have been demonstrated to increase $\mathrm{Lp}(\mathrm{a})$ concentrations by $10-20 \%$ [26, 43]. Statin use may cause cholesterol to "escape" coordination with LDL-c receptors to form more Lp(a) [44], which indicates a need to monitor populations that are treated with statins.

The impact of $\operatorname{Lp}(\mathrm{a})$ on ARAS has been raised and been seriously questioned in previous studies, as both positive and negative results have been reported [25, $26,45,46]$. Park et al. [45] performed renal arteriography at the time of cardiac catheterization in 270 patients and screened 28 ARAS ( $\geq 50 \%$ narrowing of renal artery) and 242 non-ARAS patients, concluding that $\mathrm{Lp}(\mathrm{a})$ was not associated with ARAS (median, ARAS: $143 \mathrm{mg} / \mathrm{L}$ vs. non-ARAS: $188 \mathrm{mg} / \mathrm{L}$ ). In contrast, Scoble et al. [46] examined the lipoprotein profiles in a small number of patients with $(n=32, \geq$ $30 \%$ narrowing of renal artery on angiography) or without $(n=32$, matched with ARAS patients for clinical baseline features but no angiography performed) ARAS in a case-controlled study, revealing that serum $\mathrm{Lp}(\mathrm{a})$ levels were higher in the non-ARAS group (mean $\pm \mathrm{SD}$, ARAS: $310 \pm 210 \mathrm{mg} / \mathrm{L}$ vs. nonARAS: $580 \pm 450 \mathrm{mg} / \mathrm{L} ; \quad P<0.01)$. The negative relationship between ARAS and $L p(a)$ was explained by an Apo (a) polymorphism. Zhang et al. [25] performed a cross-sectional study of 1200 Chinese patients who underwent renal arteriography immediately after coronary angiography, and found that $L p(a)$ was significantly higher in patients with mild and advanced ARAS ( $\geq 30 \%$ narrowing of renal artery) by univariate logistic regression (percentage of high serum Lp(a), ARAS: $24.2 \%$ vs. Non-ARAS: $17.5 \% ; P=$ 0.039). Catena et al. [26] examined 50 hypertensive patients with ARAS (in those with mild and advanced ARAS ( $\geq 70 \%$ narrowing of renal artery on angiography) and 58 hypertensive patients with comparable cardiovascular risk factor burden but non-ARAS (assessed by angio-MRI or angio-CT scan and/or renal angiography) in a cross-sectional study, which demonstrated that $\mathrm{Lp}(\mathrm{a})$ levels in the highest tertile had greater risk than the lowest tertile (OR: 3.70; $P=$ 0.016). Further analyzing their results, we found that some studies had insufficient sample sizes for analysis, while one study diagnosed ARAS by non-invasive imaging methods, which could have resulted in variability in patient assignment. In addition, few studies have taken the effect of $\mathrm{Lp}(\mathrm{a})$ at low LDL-c levels into account, resulting in studies with insufficient information to establish coherent conclusions. In this study, angiography was used to assess a 50\% narrowing of renal artery in order to classify patients in either the ARAS group or non-ARAS, as opposed to non-invasive imaging, and this meets the gold standard of diagnosis. In addition, the datas in this study were thoroughly and expansively collected compared to prior studies and therefore can provide higher quality evidence. It must be noted, however, that there are still some limitations to this study. Firstly, as this study utilized cross-sectional data studies, only correlations can be inferred, rather than causality, which established the findings as a reference tool for clinical practice. Secondly, a major concern of the study is the selection bias due to the strict inclusion and exclusion criteria regarding renal angiography. However, as a gold standard of ARAS, renal angiography provides a reliable prerequisite for the analysis of residual risk factor for ARAS. Using the strict criteria is an effective and valuable way to increase the homogeny of the high-risk ASCVD patients to study the residual effect of $\mathrm{Lp}(\mathrm{a})$ on ARAS. As the $\mathrm{Lp}(\mathrm{a})$ was shown to be significantly associated with the occurrence of ARAS even in high-risk ASCVD population of patients in the explorative study, we postulated that the effect of $\mathrm{Lp}(\mathrm{a})$ will be more robust in the population with lower risk. Further studies are warranted in more general population to screen potential ARAS by renal artery ultrasound examination, and validate the finding in the current study. Another concern of the study is that our sample size was relatively small. In the stratified analysis for LDL-c, 57 cases were available for low levels of LDL-c group, potentially limiting the statistical power to detect the associations and producing the extremely wide confidence intervals that we observed. However, using PASS v.13 (NCSS, LLC Kaysville, UT USA), we found that the study was able to achieve $75 \%$ power, which is acceptable. And we did find consistent effect trend and significant difference between the prevalence of ARAS and different concentrations of $\mathrm{Lp}(\mathrm{a})$ in low levels of LDL-c patients, even with the limited sample 
size. Future study with larger population is needed to increase the power of the study. Thirdly, patients with poor kidney function may also have proteinuria, causing the liver to produce more lipoprotein, including $\mathrm{Lp}$ (a) and potentially effecting serum Lp(a) levels.

Great progress has been made in understanding the role of $\mathrm{Lp}(\mathrm{a})$ in ARAS, but much remains to be explored. Patients under therapy have more clinical events of ARAS than are prevented, indicating that residual risk factors, such as $\mathrm{Lp}(\mathrm{a})$, need to be examined and taken into account. Given the potential CVD risks of $L p(a)$, treatment is now an urgent task. Great importance has been given to reducing LDL-c levels and we already have comprehensive lipid-lowering medications. Now it is high time to pay more attention to the control of $\operatorname{Lp}(\mathrm{a})$ level. The 2019 European Society of Cardiology guidelines recommend measuring $\mathrm{Lp}$ (a) concentration at least once in each adult person's lifetime and consider 180 $\mathrm{mg} / \mathrm{dL}$ of $\mathrm{Lp}(\mathrm{a})$ to be a very high inherited level that indicates danger for ACSVD (Class IIa, Grade C) [8]. It must be noted that, currently, no known medications or nutrients intake that can directly lower $\mathrm{Lp}$ (a) levels have been used [47].

\section{Conclusion}

This study revealed that a subgroup of patients with renal artery stenosis may presented with low LDL-c levels. Under this situation, high $\mathrm{Lp}(\mathrm{a})$ concentration is independently and significantly associated with ARAS and thus is a residual risk factor. This finding could be useful for the prevention and early warning of ARAS in clinical practice. Further studies will investigate the mechanism by which the $\operatorname{Lp}(\mathrm{a})$ may be leveraged for new treatments.

\section{Supplementary information}

Supplementary information accompanies this paper at https://doi.org/10. 1186/s12944-020-01272-0.

Additional file 1: Table S1. Sensitivity analysis for adjusting the confounding effect of antihypertensive and statin.

\footnotetext{
Abbreviations

ASCVD: Arteriosclerotic cardiovascular disease; CVD: Cardiovascular disease; Lp(a): Lipoprotein (a); ARAS: Atherosclerotic renal artery stenosis; PAD: Peripheral arterial disease; CAD: Coronary artery disease; BMI: Body mass index; SBP: Systolic blood pressure; DBP: Diastolic blood pressure; LDLc: Low-density lipoprotein-cholesterol; eGFR: Evaluated glomerular filtration rate; DM: Diabetes mellitus; RALL: Renal arterial lumen loss; aOR: Adjusted odds ratio; ACEls: Angiotensin converting enzyme inhibitors; ARBs: Angiotensin receptor blockers
}

\section{Acknowledgements}

We thank LetPub (www.letpub.com) for its linguistic assistance during the preparation of this manuscript.

\section{Authors' contributions}

$\mathrm{XMH}$ contributed to the data analyse and drafting of the manuscript. YX, $X D L$ and DML collected and collated the data. YLZ and HJD contributed to the ideas and critical revisions of the manuscript and approved the final version of the manuscript to submit. All authors read and approved the final manuscript.

\section{Funding}

Our research was supported by The National Key Research and Development Program of China (No. 2016YFC1301202).

\section{Availability of data and materials \\ The data set analyzed in this study can be reasonably obtained from the corresponding author.}

\section{Ethics approval and consent to participate}

This study was conducted under the guiding principles of the Declaration of Helsinki and was approved by the Clinical Research Ethics Committee of the Guangdong Provincial People's Hospital. All participants were verbally informed of the study.

\section{Consent for publication}

Not applicable.

\section{Competing interests}

The authors declare that they have no competing interests.

\section{Author details}

'Department of Cardiology, Guangdong Provincial People's Hospital, Guangdong Academy of Medical Sciences, \#96 Dongchuan Road, Guangzhou 510080, Guangdong, China. ${ }^{2}$ The Second School of Clinical Medicine, Southern Medical University, Guangzhou 510515, Guangdong, China. ${ }^{3}$ Department of Cardiology, Guangdong Provincial People's Hospital Zhuhai Hospital (Zhuhai Golden Bay Center Hospital), Zhuhai 519040, Guangdong, China. ${ }^{4}$ Department of Cardiology, Vascular Center, Guangdong Cardiovascular Institute, Guangdong Provincial Key Laboratory of Coronary Heart Disease Prevention, Guangdong Provincial People's Hospital, Guangdong Academy of Medical Sciences, \#96 Dongchuan Road, Guangzhou 510080, Guangdong, China.

Received: 2 February 2020 Accepted: 29 April 2020

Published online: 23 July 2020

\section{References}

1. Institute for Health Metrics and Evaluation (IHME). GBD results tool. GHDxhttp://ghdx.healthdata.org/gbd-results-tool; 2018.

2. Sabatine MS, Wiviott SD, Im K, Murphy SA, Giugliano RP. Efficacy and safety of further lowering of low-density lipoprotein cholesterol in patients starting with very low levels: a meta-analysis. JAMA Cardiol. 2018;3(9):823-8.

3. Di Angelantonio E, Gao P, Pennells L, Kaptoge S, Caslake M, Thompson A, et al. Lipid-related markers and cardiovascular disease prediction. JAMA. 2012;307(23):2499-506.

4. Nikpay M, Goel A, Won HH, Hall LM, Willenborg C, Kanoni S, et al. A comprehensive 1,000 genomes-based genome-wide association metaanalysis of coronary artery disease. Nat Genet. 2015;47(10):1121-30.

5. Ference BA, Yoo W, Alesh I, Mahajan N, Mirowska KK, Mewada A, et al. Effect of long-term exposure to lower low-density lipoprotein cholesterol beginning early in life on the risk of coronary heart disease: a Mendelian randomization analysis. J Am Coll Cardiol. 2012;60(25):2631-9.

6. Holmes MV, Asselbergs FW, Palmer TM, Drenos F, Lanktree MB, Nelson CP, et al. Mendelian randomization of blood lipids for coronary heart disease. Eur Heart J. 2015;36(9):539-50.

7. Silverman MG, Ference BA, Im K, Wiviott SD, Giugliano RP, Grundy SM, et al. Association between lowering LDL-C and cardiovascular risk reduction among different therapeutic interventions: a systematic review and metaanalysis. JAMA. 2016;316(12):1289-97.

8. Mach F, Baigent C, Catapano AL, Koskinas KC, Casula M, Badimon L, et al. 2019 ESC/EAS guidelines for the management of dyslipidaemias: lipid modification to reducecardiovascular risk. Eur Heart J. 2020;41(1):111-88.

9. Chapman MJ. Beyond the statins: new therapeutic perspectives in cardiovascular disease prevention. Cardiovasc Drugs Ther. 2005;19(2):135-9. 
10. Cai A, Li L, Zhang Y, Mo Y, Mai W, Zhou Y. Lipoprotein (a): a promising marker for residual cardiovascular risk assessment. Dis Markers. 2013;35(5): 551-9.

11. Shah PK. Inhibition of CETP as a novel therapeutic strategy for reducing the risk of atherosclerotic disease. Eur Heart J. 2007;28(1):5-12.

12. Campbell CY, Rivera JJ, Blumenthal RS. Residual risk in statin-treated patients: future therapeutic options. Curr Cardiol Rep. 2007;9(6):499505.

13. Kelly E, Hemphill L. Lipoprotein (a): a lipoprotein whose time has come. Curr Treat Options Cardiovasc Med. 2017:19(7):48

14. Khera AV, Everett BM, Caulfield MP, Hantash FM, Wohlgemuth J, Ridker PM, et al. Lipoprotein (a) concentrations, rosuvastatin therapy, and residual vascular risk: an analysis from the JUPITER trial (justification for the use of statins in prevention: an intervention trial evaluating Rosuvastatin). Circulation. 2014;129(6):635-42.

15. Chrysochou C, Kalra PA. Epidemiology and natural history of atherosclerotic renovascular disease. Prog Cardiovasc Dis. 2009;52(3):184-95.

16. Gloviczki ML, Glockner JF, Crane JA, McKusick MA, Misra S, Grande JP, et al. Blood oxygen level-dependent magnetic resonance imaging identifies cortical hypoxia in severerenovascular disease. Hypertension. 2011;58(6): 1066-72.

17. Guo H, Kalra PA, Gilbertson DT, Liu J, Chen SC, Collins AJ, et al. Atherosclerotic renovascular disease in older US patients starting dialysis, 1996 to 2001. Circulation. 2007;115(1):50-8.

18. Dzielińska Z, Januszewicz A, Demkow M, Makowiecka-Cieśla M, Prejbisz A, Naruszewicz M, et al. Cardiovascular risk factors in hypertensive patients with coronary artery disease and coexisting renal artery stenosis. J Hypertens. 2007;25(3):663-70.

19. Shukla AN, Madan TH, Jayaram AA, Kute VB, Rawal JR, Manjunath AP, et al Prevalence and predictors of renal artery stenosis in patients undergoing peripheral and coronary angiography. Int Urol Nephrol. 2013;45(6):1629-35.

20. Bageacu S, Cerisier A, Isaaz K, Nourissat A, Barral X, Favre JP. Incidental visceral and renal artery stenosis in patients undergoing coronary angiography. Eur J Vasc Endovasc Surg. 2011:41(3):385-90.

21. Hansen KJ, Edwards MS, Craven TE, Cherr GS, Jackson SA, Appel RG, et al. Prevalence of renovascular disease in the elderly: a population-based study. J Vasc Surg. 2002;36(3):443-51.

22. Coen G, Calabria S, Lai S, Moscaritolo E, Nofroni I, Ronga G, et al. Atherosclerotic ischemic renal disease. Diagnosis and prevalence in an hypertensive and/or uremic elderly population. BMC Nephrol. 2003:4:2.

23. Horita Y, Tadokoro M, Taura K, Mishima Y, Miyazaki M, Kohno S, et al. Relationship between carotid artery intima-media thickness and atherosclerotic renal arterystenosis in type 2 diabetes with hypertension. Kidney Blood Press Res. 2002;25(4):255-9.

24. Drummond CA, Brewster PS, He W, Ren K, Xie Y, Tuttle KR, et al. Cigarette smoking and cardio-renal events in patients with atherosclerotic renal artery stenosis. PLoS One. 2017;12(3):e0173562.

25. Zhang Y, Ge JB, Qian JY, Ye ZB. Prevalence and risk factors of atherosclerotic renal artery stenosis in 1,200 chinese patientsundergoing coronary angiography. Nephron Clin Pract. 2006;104(4):C185-92.

26. Catena C, Colussi G, Nait F, Capobianco F, Sechi LA. Plasma lipoprotein (a) levels and atherosclerotic renal artery stenosis in hypertensivepatients. Kidney Blood Press Res. 2015;40:166-75.

27. Williams B, Mancia G, Spiering W, Agabiti Rosei E, Azizi M, Burnier M, et al. 2018 ESC/ESH guidelines for the management of arterial hypertension. Eur Heart J. 2018;39(33):3021-104.

28. Cosentino F, Grant PJ, Aboyans V, Bailey CJ, Ceriello A, Delgado V, et al. 2019 ESC guidelines on diabetes, pre-diabetes, and cardiovascular diseases developed in collaboration with the EASD. Eur Heart J. 2020;41(2):255-323.

29. Patel MR, Calhoon JH, Dehmer GJ, Grantham JA, Maddox TM, Maron DJ, et al. ACC/AATS/AHA/ASE/ASNC/SCAI/SCCT/STS 2016 appropriate use criteria for coronary revascularization in patients with acute coronary syndromes : a report of the American College of Cardiology Appropriate use Criteria Task Force, American Association for Thoracic Surgery, American Heart Association, American Society of Echocardiography, American Society of Nuclear Cardiology, Society for Cardiovascular Angiography and Interventions, Society of Cardiovascular Computed Tomography, and the Society of Thoracic Surgeons. J Nucl Cardiol. 2017;24(2):439-63.

30. Chinese Cardiovascular Disease Association. Recommendations for the suitability criteria for coronary artery revascularization in China. Chin Circ J. 2016;31(04):313-7 (In Chinese).
31. Tsimikas S. A test in context: lipoprotein (a): diagnosis, prognosis, controversies, and emerging therapies. J Am Coll Cardiol. 2017;69(6):692-711.

32. Que X, Hung MY, Yeang C, Gonen A, Prohaska TA, Sun X, et al. Oxidized phospholipids are proinflammatory and proatherogenic in hypercholesterolaemic mice. Nature. 2018;558(7709):301-6.

33. van der Valk FM, Bekkering S, Kroon J, Yeang C, Van den Bossche J, van Buul JD, et al. Oxidized phospholipids on lipoprotein (a) elicit arterial wall inflammation and an inflammatory monocyte response in humans. Circulation. 2016;134(8):611-24.

34. Spence JD, Koschinsky M. Mechanisms of lipoprotein (a) pathogenicity: prothrombotic, proatherosclerotic, or both? Arterioscler Thromb Vasc Biol. 2012;32(7):1550-1.

35. Erqou S, Kaptoge S, Perry PL, Di Angelantonio E, Thompson A, White IR, et al. Lipoprotein (a) concentration and the risk of coronary heart disease, stroke, and nonvascular mortality. JAMA. 2009;302:412-23.

36. Forbes CA, Quek RG, Deshpande S, Worthy G, Wolff R, Stirk L, et al. The relationship between $L p(a)$ and CVD outcomes: a systematic review. Lipids Health Dis. 2016;15:95.

37. Thanassoulis G, Campbell CY, Owens DS, Smith JG, Smith AV, Peloso GM, et al. Genetic associations with valvular calcification and aortic stenosis. N Engl J Med. 2013;368:503-12.

38. Kamstrup PR, Tybjaerg-Hansen A, Nordestgaard BG. Elevated lipoprotein (a) and risk of aortic valve stenosis in the general population. J Am Coll Cardiol. 2014;63:470-7

39. Fogacci F, Cicero AF, D'Addato S, D'Agostini L, Rosticci M, Giovannini M, et al. Serum lipoprotein (a) level as long-term predictor of cardiovascular mortality in a large sample of subjects in primary cardiovascular prevention: data from the Brisighella heart study. Eur J Intern Med. 2017;37:49-55.

40. Albers JJ, Slee A, O'Brien KD, Robinson JG, Kashyap ML, Kwiterovich PO Jr, et al. Relationship of apolipoproteins A-1 and B, and lipoprotein (a) to cardiovascular outcomes: the AIM-HIGH trial (Atherothrombosis intervention in metabolic syndrome with low HDL/high triglyceride and impact on Global Health outcomes). J Am Coll Cardiol. 2013:62:1575-9.

41. Nestel PJ, Barnes EH, Tonkin AM, Simes J, Fournier M, White HD, et al. Plasma lipoprotein (a) concentration predicts future coronary and cardiovascular events in patients with stable coronary heart disease. Arterioscler Thromb Vasc Biol. 2013:33(12):2902-8.

42. Schmidt K, Noureen A, Kronenberg F, Utermann G. Structure, function, and genetics of lipoprotein (a). J Lipid Res. 2016;57(8):1339-59.

43. Verbeek R, Hoogeveen RM, Langsted A, Stiekema LCA, Verweij SL, Hovingh GK, et al. Cardiovascular disease risk associated with elevated lipoprotein (a) attenuates at low low-density lipoprotein cholesterol levels in a primary prevention setting. Eur Heart J. 2018;39(27):2589-96.

44. Yeang C, Witztum JL, Tsimikas S. 'LDL-C'=LDL-C $+\mathrm{Lp}$ (a)-C: implications of achieved ultra-low LDL-C levels in the proprotein convertase subtilisin/kexin type 9 era of potent LDL-C lowering. Curr Opin Lipidol. 2015;26(3):169-78.

45. Park JS, Park JH, Kang JY, Yang WS, Kim SB, Park SW, et al. Hyperfibrinogenemia is an independent risk factor for atherosclerotic renal artery stenosis. Am J Nephrol. 1999;19:649-54.

46. Scoble JE, de Takats D, Ostermann ME, Connolly JO, Scott NR, Beeso JA et al. Lipid profiles in patients with atherosclerotic renal artery stenosis. Nephron. 1999;83(2):117-21.

47. Fogacci F, Cicero AFG, D'Addato S, Giovannini M, Borghi C. Effect of spontaneous changes in dietary components and lipoprotein (a) levels: data from the Brisighella heart study. Atherosclerosis. 2017:262:202-4.

\section{Publisher's Note}

Springer Nature remains neutral with regard to jurisdictional claims in published maps and institutional affiliations. 